\title{
Protecting the brain and spinal cord in aortic arch surgery
}

\author{
Lars G. Svensson \\ Heart \& Vascular Institute, Cleveland Clinic, Cleveland, OH, USA \\ Correspondence to: Lars G. Svensson, MD, PhD. Chairman, Heart \& Vascular Institute, Cleveland Clinic, 9500 Euclid Avenue, J1-227, Cleveland, OH \\ 44195, USA. Email: svenss1@ccf.org.
}

\begin{abstract}
Protection of the central nervous system—either the brain or the spinal cord—during aortic surgery has been the subject of intense research over the past several decades. While it took some 30 years to prove that some of the techniques first practiced in animals are valuable, surgeons can now take courage from 50 years of research that has resulted in superb outcomes, particularly when compared with historical results. Complex total arch operations and descending aortic operations can now be performed with less than a $2 \%$ rate of stroke, spinal cord injury, or death. Thoracoabdominal aortic operations and endovascular procedures have also become considerably safer with excellent results reported. The following review will discuss some of the historical outcomes, innovations, iterations, current techniques, and outcomes.
\end{abstract}

Keywords: Aortic arch; brain protection

Submitted Jan 04, 2018. Accepted for publication May 01, 2018.

doi: $10.21037 /$ acs.2018.05.01

View this article at: http://dx.doi.org/10.21037/acs.2018.05.01

\section{Introduction}

The volume of aortic surgeries performed at this institute has progressively increased over time, from about 190 thoracic aortas in the early 2000's, to now some 750 . Concurrently, open abdominal and even endovascular procedures have declined, as abdominal aortic stenting has become more of a commodity. This review illustrates a breakdown of total aortic procedures for the past year, consisting of some 1,200 patients, the majority comprising ascending and arch operations.

\section{Review}

The quandary of how to go about aortic arch protection during circulatory arrest has been on-going for quite some time. Figure 1 is based on a study (1) conducted many years ago on Dr. Stanley Crawford's patients, which showed that after 40 minutes of circulatory arrest, but with deep hypothermia alone, the risk of stroke increased. More recent studies support that 40 minutes of circulatory arrest is the maximum (2). If a procedure can be completed in less than $25-30$ minutes, with hypothermia less than $20^{\circ} \mathrm{C}$ on nasopharyngeal measurement, then this can be safely done.
In 1971, Dr. Liotta (3) published on the first left ventricular assist devices (LVADs), with operations completed by Stanley Crawford (Figure 2). In these procedures, a side graft was sewn onto the subclavian artery for the arterial inflow for the LVAD. This prompted the use of the subclavian side graft with a tube graft to the artery (4). Furthermore, cannulas were inserted directly into the subclavian or axillary artery and Gundry balloon catheters were placed into the innominate and carotid arteries, so that measurement of arterial pressure could take place. In a study (5) of some 1,300 patients undergoing operations with deep hypothermia circulatory arrest, it was found that the more complex the operation, the greater risk for stroke and mortality, as is to be expected. The overall stroke rate was $6.1 \%$, but reduced by $40 \%$ when the subclavian side-graft was utilized. Propensity matching demonstrated benefit over direct cannulation of the subclavian versus femoral or direct arch cannulation. This illustrates the importance of using perfusion via a side graft to the subclavian artery in brain protection.

A more recent randomized trial of 121 patients undergoing total arch replacement compared antegrade and retrograde brain perfusion (6). The outcomes were somewhat surprising; the clinical stroke and mortality rate 


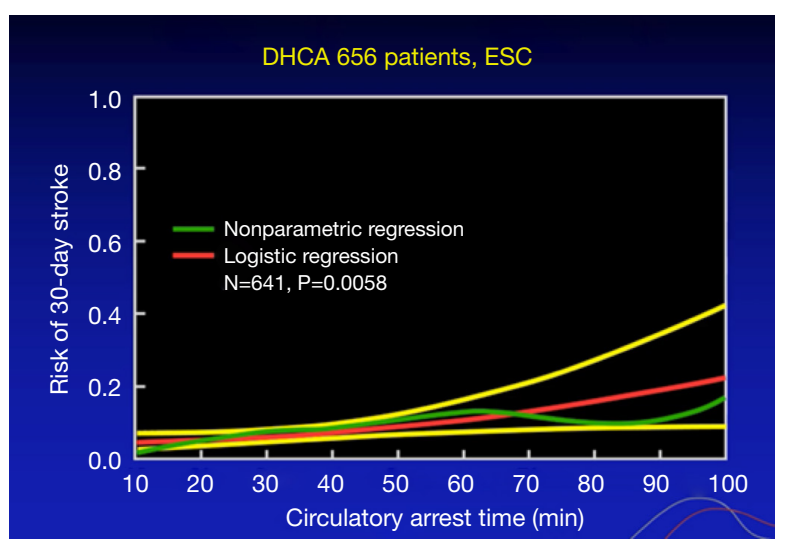

Figure 1 Deep hypothermic circulatory arrest correlated with increased risk of 30-day stroke.

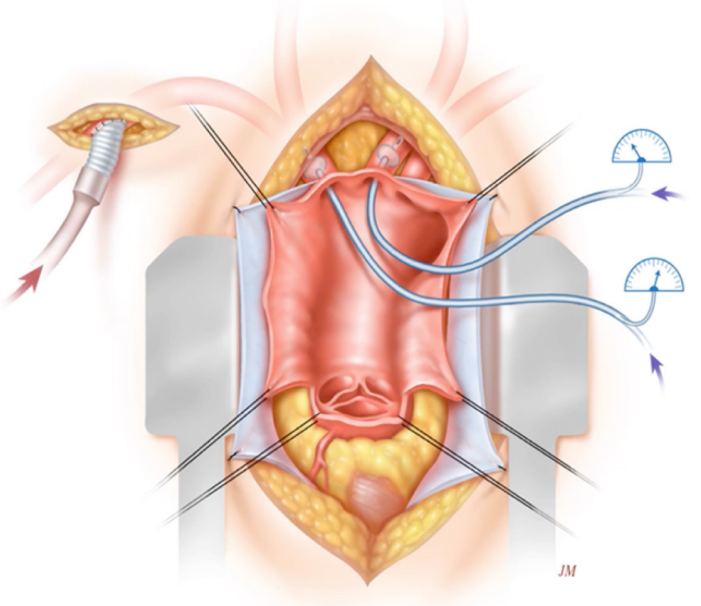

Figure 2 Side graft utilization with a tube graft, and Gundry balloon catheter insertion into the innominate and carotid arteries to allow for arterial pressure measurement.

was reported to be only $0.8 \%$. In this study, preoperative and postoperative neurocognitive testing and imaging were also conducted. It was found that neurocognitive testing and imaging was obviously more sensitive than clinical diagnosis for brain injury. In this trial, a number of brain protection methods were employed, according to the literature $(4,7,8)$ : the patients were cooled to less than $20^{\circ} \mathrm{C}$ nasopharyngeal temperature; double coolers were used for both rapid cooling and rewarming; the patients were placed in steep head down position; heads were packed in ice; and $\mathrm{CO}_{2}$ flooding at $10 \mathrm{~L}$ per minute was utilized. This final step aids in the removal of any potential gaseous material. The subclavian side graft inflow allowed pressures to be maintained at $40-60 \mathrm{mmHg}$ during antegrade perfusion. This was done every 15 minutes for 5 minutes each time, so this was (6) not a true continuous antegrade perfusion. Nonetheless, the current literature has shown that intermittent antegrade brain perfusion is a very safe method for performing both pediatric circulatory arrest surgery and also for pulmonary endarterectomy on the pulmonary arteries. Continuous retrograde brain perfusion at 20-30 $\mathrm{mmHg}$ was also employed (1).

Postoperative neurological examination was performed by consultant neurologists, as well as pre-operative and post-operative MRIs and neurocognitive testing. On imaging studies, stroke or change on the MRIs/CTs were found in $15 \%$ of patients and $18 \%$ had a neurocognitive decline, typically 3-4 months after the procedure. Both of these totaled a $24 \%$ change. Some changes obviously were very subtle, but on more careful testing-either with imaging or neurocognitive function assessmentsthese were detected. There were no differences between antegrade and retrograde brain perfusion. The radiological strokes that were in the posterior brain, cerebellar area or occipital area were often silent when it came to either neurologic examination or neurocognitive testing. On the other hand, the results from neurocognitive testing sometimes did not correlate with those from imaging did not correlate with those from imaging.

\section{Elephant trunk procedure}

Initially (8), an elephant trunk procedure was performed with a side graft attached (9) and then used for antegrade brain perfusion. The problem with this is that any potential gaseous material within the greater arteries is not flushed out. This is one of the clear benefits of subclavian artery perfusion (10). More recently (11), the procedures for the aortic arch elephant trunk operations, dependent upon where the anastomosis is done, have been classified. Type I is beyond the subclavian; Type II is between the subclavian and the carotid; Type III is distal arch with only the distal arch being operated on; Type IV describes debranching or doing separate bypasses to the greater vessels; and then Type $\mathrm{V}$ is where an anastomosis has been performed in the ascending aorta with a more distal elephant trunk procedure. Obviously, each of these can be done as a frozen elephant trunk at the first procedure in order to avoid doing a second operation (Figure 3). An important point to remember about these variations is to sew the elephant trunk to the back of the graft that is branched to the greater 


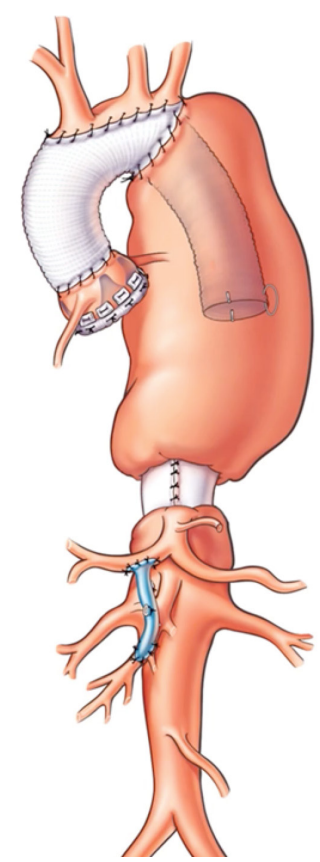

Figure 3 Elephant trunk procedure with distal components.

vessel. This prevents kinking of the elephant trunk graft. The frozen elephant trunks for acute dissection are also an option $(12,13)$.

In our center, a number of patients were operated on such that entire aortas were replaced during a single operation, with a mortality rate of $17 \%$ (14). Though it was feasible and could be done, this high mortality rate was a problem. This resulted in a shift back towards the elephant trunk procedure for these types of operations. For patients having $2^{\text {nd }}$ stage procedures or endovascular distal thoracic procedures, including the aortic arch, 673 endovascular procedure patients were completed as of 2013, with a quarter of those being emergencies or urgent. A sizeable number were operations on the descending aorta, but also included varying extents of the thoracic aorta as well. Crawford Type IVs were excluded from this study. In $16 \%$ of subjects, the arch was covered. Seventeen percent were debranched and fenestrated grafts were utilized in $34 \%$. Cerebrospinal fluid (CSF) drainage was used in about $58 \%$ and the endovascular placement had a $98 \%$ success rate. There was access injury in $13 \%$, paralysis in $6.1 \%$, permanent stroke in $4.4 \%$ and $10 \%$ developed renal failure. The primary factors that predicted mortality were namely: female, age, renal failure, previous open-heart surgery, emergency and arch involvement. The late predictors were dialysis, dissection, aortic size, coronary disease, pacemaker, thoracoabdominal aneurysms-particularly more extensive - and distal descending aorta involvement. Stroke was predicted by renal failure, non-elective surgery and the earlier time period. Paralysis was predicted by age, thoracoabdominal involvement, previous abdominal aneurysm replacement-something known for quite some time for open procedures and use of iliac conduits. The survival rate was not particularly good at $56 \%$ at 5 years after follow-up.

Another study (16) took place where $2^{\text {nd }}$ stage elephant trunk procedures, either open or endovascular, were assessed in detail. They were very similar, but endovascular patients required more interventions. Long term survival showed that there was no difference between the two after 6 years; perhaps there is some divergence, with the open subjects having worse early mortality, but better long-term survival. In summary, though the two groups outcomes were somewhat similar in terms of survival, more interventions were needed in the endovascular group.

For cerebral and spinal cord protection whilst working through the left side during arch operations, the approach that has been found to be most useful is to sew a side graft to the subclavian artery, and then use femoral venous drainage alongside perfusion with the femoral artery distally. This technique allows for aortic arch operations with circulatory arrest whilst protecting the spinal cord. This further reduces the risk of stroke. Once the arch is done, the proximal anastomosis can be carried out if required. The pulmonary artery can also be divided to confer access proximally. This approach has some good success rates. It has been known for quite a while now, based on Dr. Crawford's work, that the extent of thoracoabdominal aneurysm predicts the spinal cord outcome (17). There is some predictability too for spinal cord injury during thoracic aorta repairs, correlated with the extent of disease in the descending aorta (18). Classically, Dr. Crawford used clamped, sewed and perfused the visceral vessels and the visceral vessels. This practice has been avoided in more recent times as dissection or damage to the arteries would often occur. Direct cooling of the kidneys with saline at $180 \mathrm{cc}$ was found to be very effective in protecting renal function in these procedures (19). A prospective randomized trial by Dr. Joseph Coselli found equivalent results with infusion of either cold saline or cold blood into the kidneys (20).

After approximately 40 minutes of cross-clamping in descending aortic repairs (18), distal perfusion with atrial femoral bypass is protective; hence our institute shifted towards cooling patients whilst using atrial femoral bypass 


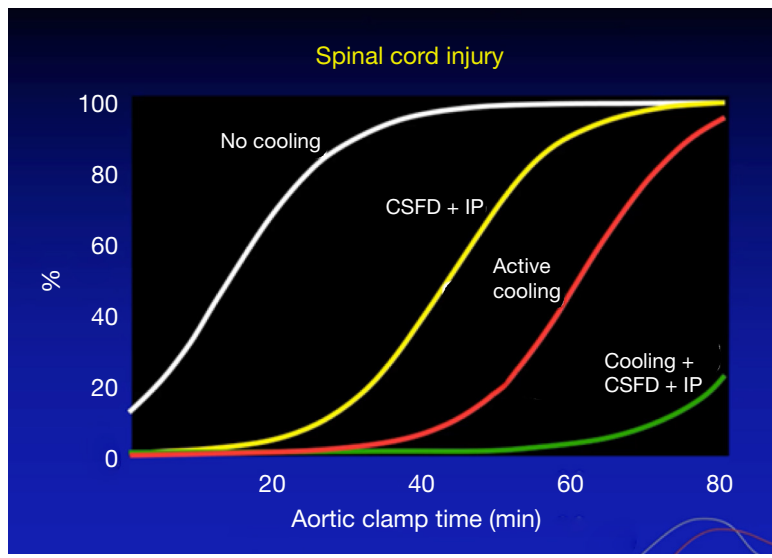

Figure 4 Spinal cord injury across different techniques of protection. CSFD, cerebrospinal fluid drainage; IP, intrathecal papaverine.

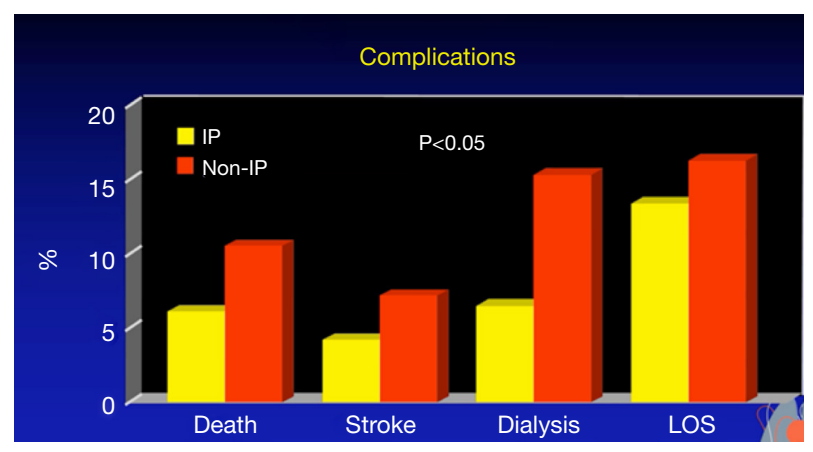

Figure 5 Complication rates between IP vs. non-IP. IP, intrathecal papaverine; LOS, length of stay.

(Figure 4). In the paper (17) on Dr. Crawford's patients, there were 1,509 thoracoabdominal aneurysm repairs. The rate of paraplegia for Type I was $15 \%$, Type II was $30 \%$, Type III was $15 \%$ and Type IV was $4 \%$. Figure 5 shows our promising results, particularly when viewed from a historical perspective. As can be seen from the data produced by Dr. Coselli (20-22), the risks have been considerably reduced by CSF drainage and other such techniques. Intrathecal papaverine with CSF drainage was also helpful in reducing paralysis by half (23). Dr. Crawford's patients also went through a period where he wanted to keep them normothermic, resulting in a higher risk of paralysis. This risk of paralysis related to cross-clamp time was shown for all of Dr. Crawford's patients.

A number of human and animal studies were carried out looking at spinal cord anatomy and where the artery of Adamkiewicz deviates, also known as the arteria radicularis magna (ARM), originates in the lower thoracic aorta (24). In most patients, it was thought to be important for preservation in thoraco-abdominal repairs. With atrial femoral bypass, or aorta femoral bypass, it was found that one could inject blood into the pump and show that the spinal cord was perfused distally (25). In the animal experiments (26), intrathecal papaverine with CSF drainage was highly successful in improving blood supply to the spinal cord after 60 minutes of cross clamping, also aiding in preventing paraplegia in all animals that had this procedure (Figure 4). The results are presented in the paper "Systemic temperature and paralysis after thoracoabdominal and descending aortic operations" (27). The patients with CSF drainage and with intrathecal papaverine had the lowest risk.

A study of some 400 patients evaluating at their risk of having paralysis was carried out (23). Propensity score matching found that in both the matched and the unmatched groups, the risk of paralysis was reduced by use of intrathecal papaverine and CSF drainage. This also had a more of a predictable effect on the Type I and Type II thoracoabdominal aneurysms. The rate of permanent neurological deficits was reduced by using intrathecal papaverine and CSF drainage. The incidence of complications was also lower (Figure 5). It is known that paralysis is associated with more complications, so that is not too surprising. Long term survival was better in patients that had intrathecal papaverine.

\section{Conclusions}

In summary, intrathecal papaverine enhances the protection of the spinal cord and is associated with reduced postoperative complications in aortic surgery patients. The other clinical implications are-other than for using it in open procedures-that intrathecal papaverine should be used in TEVAR. As illustrated by the aforementioned studies, CSF drainage during TEVAR is routine and concurrent implementation of intrathecal papaverine is being considered.

\section{Acknowledgements}

Dr. Svensson would like to thank Ashley Wilson-Smith for the assistance in editing this manuscript.

\section{Footnote}

Conflicts of Interest: The author has no conflicts of interest to 
declare.

\section{References}

1. Svensson LG, Crawford ES, Hess KR, et al. Deep hypothermia with circulatory arrest. Determinants of stroke and early mortality in 656 patients. J Thorac Cardiovasc Surg 1993;106:19-28; discussion 28-31.

2. Damberg A, Carino D, Charilaou P, et al. Favorable late survival after aortic surgery under straight deep hypothermic circulatory arrest. J Thorac Cardiovasc Surg 2017;154:1831-9.e1.

3. Liotta D, Crawford ES, Cooley DA, et al. Prolonged partial left ventricular bypass by means of an intrathoracic pump implanted in the left chest. Trans Am Soc Artif Intern Organs 1962;8:90-9.

4. Svensson LG, Nadolny EM, Kimmel WA. Multimodal protocol influence on stroke and neurocognitive deficit prevention after ascending/arch aortic operations. Ann Thorac Surg 2002;74:2040-6.

5. Svensson LG, Blackstone EH, Rajeswaran J, et al. Does the arterial cannulation site for circulatory arrest influence stroke risk? Ann Thorac Surg 2004;78:1274-84.

6. Svensson LG, Blackstone EH, Apperson-Hansen C, et al. Implications from neurologic assessment assessment of brain protection for total arch replacement from a randomized trial. J Thorac Cardiovasc Surg 2015;150:1140-7.e11.

7. Svensson LG, Nadolny EM, Penney DL, et al. Prospective randomized neurocognitive and S-100 study of hypothermic circulatory arrest, retrograde brain perfusion, and antegrade brain perfusion for aortic arch operations. Ann Thorac Surg 2001;71:1905-12.

8. Svensson LG. Rationale and technique for replacement of the ascending aorta, arch, and distal aorta using a modified elephant trunk procedure. J Card Surg 1992;7:301-12.

9. Borst HG, Walterbusch G, Schaps D. Extensive aortic replacement using "elephant trunk" prosthesis. Thorac Cardiovasc Surg 1983;31:37-40.

10. Svensson LG, Kim KH, Blackstone EH, et al. Elephant trunk procedure: newer indications and uses. Ann Thorac Surg 2004;78:109-16.

11. Svensson LG, Rushing GD, Valenzuela ES, et al. Modifications, classification, and outcomes of elephant trunk procedures. Ann Thorac Surg 2013;96:548-58.

12. Roselli EE, Idrees JJ, Bakaeen FG, et al. Evolution of simplified frozen elephant trunk repair for acute DeBakey
Type I dissection: Midterm Outcomes. Ann Thorac Surg 2018;105:749-55.

13. Roselli EE, Loor G, He J, et al. Distal aortic interventions after repair of ascending dissection: the argument for a more aggressive approach. J Thorac Cardiovasc Surg 2015;149:S117-24.e3.

14. Svensson LG, Shahian DM, Davis FG, et al. Replacement of entire aorta from aortic valve to bifurcation during one operation. Ann Thorac Surg 1994;58:1164-6.

15. Resch TA, Greenberg RK, Lyden SP, et al. Combined staged procedures for the treatment of thoracoabdominal aneurysms. J Endovasc Ther 2006;13:481-9.

16. Roselli EE, Subramanian S, Sun Z, et al. Endovascular versus open elephant trunk completion for extensive aortic disease. J Thorac Cardiovasc Surg 2013;146:1408-16; discussion 1416-7.

17. Svensson LG, Crawford ES, Hess KR, et al. Experience with 1509 patients undergoing thoracoabdominal aortic operations. J Vasc Surg 1993;17:357-68; discussion 368-70.

18. Svensson LG, Crawford ES, Hess KR, et al. Variables predictive of outcome in 832 patients undergoing repairs of the descending thoracic aorta. Chest 1993;104:1248-53.

19. Svensson LG, Coselli JS, Safi HJ, et al. Appraisal of adjuncts to prevent acute renal failure after surgery on the thoracic or thoracoabdominal aorta. J Vasc Surg 1989;10:230-9.

20. Lemaire SA, Jones MM, Conklin LD, et al. Randomized comparison of cold blood and cold crystalloid renal perfusion for renal protection during thoracoabdominal aortic aneurysm repair. J Vasc Surg 2009;49:11-9; discussion 19.

21. Coselli JS, Rosu C, Amarasekara HS, et al. Reoperative surgery on the thoracoabdominal aorta. J Thorac Cardiovasc Surg 2018;155:474-85.e1.

22. Coselli JS, de la Cruz KI, Preventza O, et al. Extent II Thoracoabdominal aortic aneurysm repair: How I do it. Semin Thorac Cardiovasc Surg 2016;28:221-37.

23. Lima B, Nowicki ER, Blackstone EH, et al. Spinal cord protective strategies during descending and thoracoabdominal aortic aneurysm repair in the modern era: the role of intrathecal papaverine. J Thorac Cardiovasc Surg 2012;143:945-52.e1.

24. Svensson LG, Klepp P, Hinder RA. Spinal cord anatomy of the baboon - comparison with man and implications for spinal cord blood flow during thoracic aortic crossclamping. A Afr J Surg 1986;24:32-4.

25. Svensson LG, Patel V, Robinson MF, et al. Influence of preservation or perfusion of intraoperatively identified 
spinal cord blood supply on spinal motor evoked potentials and paraplegia after aortic surgery. J Vasc Surg 1991;13:355-65.

26. Svensson LG, Von Ritter CM, Groeneveld HT, et al. Cross-clamping of the thoracic aorta. Influence of aortic shunts, laminectomy, papaverine, calcium channel blocker, allopurinol, and superoxide dismutase on spinal cord blood flow and paraplegia in baboons. Ann Surg 1986;204:38-47.

27. Svensson LG, Khitin L, Nadolny EM, et al. Systemic temperature and paralysis after thoracoabdominal and descending aortic operations. Arch Surg 2003;138:175-9; discussion 180 .

Cite this article as: Svensson LG. Protecting the Brain and spinal cord in aortic arch surgery. Ann Cardiothorac Surg 2018;7(3):345-350. doi: 10.21037/acs.2018.05.01 